\title{
Investigating Friendship Difficulties in the Pathway from ADHD to Depressive Symptoms. Can Parent-Child Relationships Compensate?
}

\author{
Victoria Powell ${ }^{1}$ - Lucy Riglin ${ }^{1} \cdot$ Terry Ng-Knight $^{2} \cdot$ Norah Frederickson $^{3} \cdot$ Katherine Woolf $^{3} \cdot$ Chris McManus $^{3}$. \\ Stephan Collishaw ${ }^{1} \cdot$ Katherine Shelton $^{1} \cdot$ Anita Thapar $^{1} \cdot$ Frances Rice $^{1}$
}

Accepted: 21 February 2021 / Published online: 2 March 2021

(C) The Author(s) 2021

\begin{abstract}
Attention deficit/hyperactivity disorder (ADHD) is associated with friendship difficulties. This may partly account for the increasingly recognised association between ADHD and subsequent depression. Little is known about the types of friendship difficulties that could contribute to the association between ADHD and depressive symptoms and whether other relationships, such as parent-child relationships, can mitigate against potential adverse effects of friendship difficulties. In a representative UK school sample $(n=1712)$, three main features of friendship (presence of friends, friendship quality and characteristics of the individual's classroom friendship group) were assessed in a longitudinal study with two assessment waves (W1, W2) during the first year of secondary school (children aged 11-12 years). These friendship features (W1) were investigated as potential mediators of the prospective association between teacher-rated ADHD symptoms (W1) and self-rated depressive symptoms (W2) seven months later. Parent-child relationship quality (W1) was tested as a moderator of any indirect effects of ADHD on depression via friendship. ADHD symptoms were inversely associated with friendship presence, friendship quality and positive characteristics of classroom friendship groups. Depressive symptoms were inversely associated with presence and quality of friendships. Friendship quality had indirect effects in the association between ADHD and subsequent depressive symptoms. There was some evidence of moderated mediation, whereby indirect effects via friendship quality attenuated slightly as children reported warmer parent-child relationships. This highlights the importance of considering the quality of friendships and parent-child relationships in children with ADHD symptoms. Fostering good quality relationships may help disrupt the link between ADHD symptomology and subsequent depression risk.
\end{abstract}

Keywords ADHD $\cdot$ Depression $\cdot$ Friendship $\cdot$ Peer $\cdot$ Parent-child relationship $\cdot$ Transition

\section{Introduction}

Attention Deficit/Hyperactivity Disorder (ADHD) is a DSM-5 (American Psychiatric Association, 2013) defined neurodevelopmental disorder that is associated with a range of long term adverse outcomes, including employment and education difficulties, interpersonal problems, substance abuse, suicide and depression (Harpin, 2005; Ljung et al., 2014; Meinzer et al., 2014). There is strong evidence that

Victoria Powell

powellv@ cardiff.ac.uk

Cardiff University, Cardiff, UK

2 University of Surrey, Guildford, UK

3 University College London, London, UK
ADHD precedes depression in a way that is consistent with a potentially causal relationship (Riglin et al., 2020), but the mechanisms that might explain the relationship between ADHD and later depression are unclear. ADHD impacts on many aspects of a young person's life, including functioning in social, school and home life (Harpin, 2005), that might in turn increase the risk of subsequent depression. For instance, ADHD is associated with increased difficulties in friendships (Mikami, 2010). Studies comparing children with an ADHD diagnosis to typically developing controls show that children with ADHD are likely to have fewer stable friendships (Blachman \& Hinshaw, 2002; Marton et al., 2015) and may be more likely to be friends with individuals reported as having a learning or behaviour problem (Marton et al., 2015). Friendship difficulties such as poor quality 
friendships may be risk factors for subsequent depression (Goodyer et al., 1989).

One potential explanation of the prospective association of ADHD and depression is that social stressors that commonly accompany ADHD, such as friendship difficulties, lead to an increased risk of depression (Capaldi, 1992), potentially by creating feelings of failure or lowered selfesteem (Cole, 1990; Patterson \& Stoolmiller, 1991). Interpersonal stress is an important precipitator of depression, particularly during adolescence (Flynn \& Rudolph, 2011) - a period when individuals spend increasing amounts of time with friends (Larson \& Richards, 1991). Studies have shown that bullying (Roy et al., 2015), social stress (Humphreys et al., 2013) and peer-relationship difficulties (Powell et al., 2020) contribute to the prospective relationship of ADHD and depressive symptoms in young people. However, a detailed investigation of friendship features including presence of friends, friendship quality and characteristics of the friendship group (Bukowski et al., 1996) and how these are associated with ADHD and impact on later depression is lacking (Mikami, 2010; Mrug et al., 2012). Important features of friendship include whether an individual has friends, the quality of these friendships including the level of companionship and closeness, as well as the characteristics of the people that an individual is friends with (Bukowski et al., 1996). It is possible that some of these features of friendship might be more important than others in the association of ADHD and depression. For instance, a previous study conducted in secondary school children found that while retaining your best friend over time was not associated with emotional outcomes, retaining poor quality friendships over time with your top three friends was associated with subsequent emotional problems (Ng-Knight et al., 2019). The potential role of friendships in the prospective association between ADHD and depression may also differ by sex. For example, adolescent females have been found to value aspects of friendship such as companionship more highly than males, while adolescent males have been found to value the status of their peers more highly (Hall, 2010). Identification of factors that might explain the relationship between ADHD and depression, as well as factors that moderate risk, could help pinpoint new ways of supporting young people with ADHD.

School is a key context where children make friends (Ng-Knight et al., 2019). Classroom expectations including sustained concentration on tasks, following rules and self-regulation of emotions and behaviour may often be a poor 'fit' for those with ADHD, which can exacerbate poor social outcomes for this group (Richardson et al., 2015). The transition from primary to secondary school is a period of change (Chung et al., 1998) when good friendships can protect against poor mental health (Ng-Knight et al., 2019), but also when there is a natural disruption to established friendships and a need to establish new ones.
In addition to friendships, it is important to consider children's other sources of social support including parentchild relationships, which can mitigate against poor mental health outcomes in the presence of adversity (Collishaw et al., 2016). Some research suggests a compensatory model, whereby children with low levels of warmth from peers showed better adjustment outcomes in the presence of high parental warmth compared to low parental warmth (Stocker, 1994). Warmer relationships with parents are also associated with more satisfactory friendships in young people (Deković $\&$ Meeus, 1997), and the influence of parental behaviour on the child's friendships may be particularly important in children with ADHD (Mikami et al., 2010). Thus, it is possible that any mediating effects of friendship in the association of ADHD and depression could be moderated by the quality of the parent-child relationship. However, parent-child relationships are often not considered in studies of ADHD and friendship (Mikami, 2010) and this is especially the case for the father-child relationship (Cabrera et al., 2018). Investigating the influence of relationships with both mother and father is important, as they may exert differential influences on children's friendships (Flynn et al., 2018; Updegraff et al., 2001). For example, a previous study found that mother supportive behaviour and hostile behaviour, and father problemsolving behaviour and hostile behaviour, influenced their adolescent children's interaction styles with peers (Flynn et al., 2018).

The aim of this study was to investigate which aspects of friendship (presence of friends, friendship quality and characteristics of friends) are important in increasing vulnerability to depressive symptoms in those with elevated ADHD symptoms. A secondary aim of this study was to investigate whether any indirect effects via elements of friendship were moderated by mother-child or father-child relationship quality. A follow-up exploratory research question was whether indirect effects differed according to sex. The study included children in the first year of secondary school followed over a seven-month timespan.

\section{Methods}

\section{Sample}

The School Transition Adjustment Research Study (STARS; $\mathrm{Ng}$-Knight et al., 2016) includes pupils recruited from nine secondary schools in Greater London selected to be representative of schools in the local region in terms of socioeconomic disadvantage, exam pass rates and proportions of pupils from minority ethnic backgrounds. Ethical approval was granted by the University College London Research Ethics Committee. At both assessment waves, informed assent was obtained at school for the participating children 
and parents were given the opportunity to opt-out. Baseline data were collected during the second half of the first term of year 7 (children aged 11-12 years; pupil and teacher reports) and follow-up data seven months later in the summer term of year 7 (pupil reports) via questionnaires completed in classroom settings. At baseline, 1712 children participated $(53.5 \%$ male; response rate $=87.0 \%)$. For $80.1 \%$ of these children, teachers returned questionnaires reporting on the child's mental health $(n=1372)$. For 1020 of these 1372 children $(74.3 \%)$, teachers completed the section rating the children's baseline ADHD symptoms. Of the 1020 children, self-rated depressive symptom data at follow-up were available for 901 . Of these, there were 752 (50.3\% male) for whom data were additionally available on friendship and sociodemographic variables. To address bias that might be caused by missingness, predictors of missingness were investigated (Supplement 1) and missing data were imputed for covariates and outcome using Multiple Imputation by Chained Equations (MICE; White et al., 2011) with 100 imputations, which formed the analysis sample $(n=1712$; Supplement 2).

\section{Measures}

\section{ADHD Symptoms}

ADHD symptoms were measured at baseline with the teacher-rated hyperactivity-inattention subscale of the Strengths and Difficulties Questionnaire (SDQ; Goodman, 1997). Five items were rated "Not True" (0), "Somewhat True" (1) or "Certainly True" (2) (total score range $=0-10$; Cronbach alpha $=0.82$ ). The teacher-rated hyperactivityinattention subscale is a useful and valid screening tool for ADHD symptoms (Goodman, 1997) with good sensitivity and specificity for detecting DSM-IV (American Psychiatric Association, 1994) ADHD in school-aged children (Goodman et al., 2000; Ullebø et al., 2011). In UK secondary schools, children are typically taught by different teachers for different subjects. Children usually attend a daily registration group led by the same teacher throughout the school year (the form tutor). Form tutors completed the teacher questionnaire, including the SDQ.

\section{Depressive Symptoms}

Depressive symptoms were assessed at follow-up with the self-rated Short Moods and Feelings Questionnaire (SMFQ; Angold et al., 1995). Thirteen items were rated "Not true" (0), "Somewhat true" (1), or "True" (2) (total score range $=0-26$; Cronbach alpha $=0.91)$. The SMFQ is a wellvalidated, reliable measure of depression in adolescents with high sensitivity and specificity for detecting major depressive disorder (MDD) (Thapar \& McGuffin, 1998).

\section{Friendship Presence}

At baseline and follow-up, children were asked to name up to three friends in order of preference as their top 3 friends. This method was used to indicate the presence of close friends, as used previously (e.g., Fowler et al., 2007; NgKnight et al., 2019). The following variables were derived: number of friends at baseline (range $=0-3$ ), stability of best friend (from the start to the end of the school year; $0=$ no, $1=y e s$ ) and stability of 'top three friends' (stability of any of the three top friends; $0=$ no, $1=$ yes). This method of deriving friendship stability has also been used previously (Ng-Knight et al., 2019).

\section{Friendship Quality}

For their best friend, children completed a 15 -item version of the Friendships Qualities Scale, a reliable measure of five different aspects of friendship quality, at baseline (FQS; Bukowski et al., 1994). The FQS consists of five subscales: companionship, conflict, closeness, help and security. Items were rated on a 5-point Likert scale from "Not at all" (0) to "Very much" (4). Positive scales (companionship, closeness, help and security) were summed and then negative scales (conflict) subtracted to generate a maximum total quality score of 48 . The Cronbach alpha suggested that this score is reliable (0.85), as did the omega value (0.85), which does not assume one-dimensionality or equal contribution of each item to the total score (Deng \& Chan, 2017). In addition, friendship quality across the top three friends was measured at baseline by a single rating for each of these friends on a 5-point smiley face rating scale from 0 (least satisfied) to 4 (most satisfied). Scores for the top three friends were summed to give an overall score (maximum $=12$ ).

\section{Classroom Friendship Group Characteristics}

Sociometric methods were used to identify classroom friendship groups at baseline. In classroom groups, children were asked to draw on paper a diagram describing "which children in your class hang around together" by circling groups of pupils who are friends (example shown in Supplement 3). Social Cognitive Mapping software (SCM; Cairns \& Cairns, 1994; Hamm et al., 2011) was used to identify classroom friendship groups - a reliable, valid tool for this purpose (Cairns et al., 1988, 1995). To describe the characteristics of the classroom friendship group, this was linked to information on the behavioural and emotional characteristics of children in that group: (i) the self-rated SDQ total difficulties score (Goodman, 1997), and (ii) cooperative and disruptive behaviour rated by peers who indicated from a list of the children in their class who they felt matched these descriptions (example shown in Supplement 4; the Guess Who 
peer-nomination method; Coie \& Dodge, 1988; Parkhurst $\&$ Asher, 1992). Classroom friendship group characteristics were derived for each child by averaging the scores of the other pupils in their friendship group (the score of the individual was not included to avoid group scores being biased by the individual's own score). The mean number of individuals in a classroom friendship group was 5 (maximum: 15). A small number (5.3\%) of children were social isolates (i.e., did not have a classroom friendship group) so their scores could not be calculated.

\section{Parent-Child Relationship Quality}

At baseline, children who reported being in contact with their mother and/or father (or equivalents, e.g., stepparent, carer) in the last month completed a measure assessing their perception of each parent's warmth and hostility towards them using the Iowa family interaction rating scale (Melby \& Conger, 2001). The warmth scale consisted of six items (example: "Acts loving and affectionate toward you") rated on a 6-point Likert scale from "Never" (0) to "Always" (6) (score range $=0-36$; Cronbach's alpha for mother score $=0.90 ;$ Cronbach's alpha for father score $=0.92$ ). The hostility scale consisted of 4 items (example: "Criticises you or your ideas") rated in the same way (score range $=0-24$; Cronbach's alpha for mother score $=0.79$; Cronbach's alpha for father score $=0.82$ ).

\section{Confounders}

Analyses were adjusted for sex and socioeconomic and ethnic factors associated with depression (Gilman et al., 2002; Williams et al., 2015). These were socioeconomic disadvantage (free school meals status), Black Minority Ethnic status and English as a first language (data collected from school records).

\section{Data Analysis}

Analysis was conducted in STATA (version 13). All analyses presented are adjusted for confounders by including these variables in the models as covariates.

\section{Associations of ADHD, Features of Friendship and Depression}

ADHD symptoms were standardised meaning a point increase in SDQ hyperactivity score was equivalent to a standard deviation unit increase. Linear regression was used to test the association between ADHD symptoms and depressive symptoms 7 months later. Separate linear and logistic regressions were used as appropriate to test associations between ADHD symptoms and indicators of three friendship elements (presence/stability, quality, and characteristics of friends), and to test associations of these friendship indicators (standardised if continuous) with depressive symptoms. Regressions included the school class as a random effect to account for potential hierarchical data structure or clustering.

\section{Indirect Effects via Friendship in the ADHD-Depression Association}

To test whether the different features of friendship contributed to the association of ADHD and depressive symptoms, indirect effects were tested separately using the [sureg] STATA command. Sureg conducts Seemingly Unrelated Regressions (Zellner, 1962), from which indirect (mediated) and conditional indirect (moderated mediation) effects can be derived in original and imputed data (UCLA Statistical Consulting Group n.d.). Any friendship variables found to have significant indirect effects were tested simultaneously in a multiple mediator model. As indirect effects via friendship may differ according to sex (Hall, 2010), a sensitivity analysis testing moderated mediation by the child's sex was conducted using [sureg].

\section{Moderation of Indirect Effects by Parent-Child Relationships}

Moderated mediation was tested using [sureg] to investigate whether any indirect effects via friendship varied according to the warmth or hostility of parent-child relationships. The model used tested combined moderation of the pathway from ADHD symptoms to friendship and the pathway from friendship to depression symptoms (Preacher et al., 2007). Indirect effects at the mean level of the moderator and 1 standard deviation above and below this were calculated and plotted. For each moderator, significance tests ( $Z$-tests) of the difference between the observed indirect effect at the mean level of the moderator compared to the mean level of the moderator $-1 \mathrm{SD}$ (for hostility) or +1SD (for warmth) were conducted. To investigate which path(s) in the indirect effects were being moderated, we additionally tested models with an interaction effect on the path between ADHD symptoms and friendship or the path between friendship and depression symptoms only.

\section{Results}

Descriptive statistics are shown in Table 1. 
Table 1 Descriptive Statistics

\begin{tabular}{llll}
\hline Variable & $\begin{array}{l}\text { Overall mean } \\
(\mathrm{SE}) / \text { proportion } \\
(\%)\end{array}$ & $\begin{array}{l}\text { Female mean } \\
(\mathrm{SE}) / \text { proportion } \\
(\%)\end{array}$ & $\begin{array}{l}\text { Male mean (SE) } \\
\text { / proportion (\%) }\end{array}$ \\
\hline ADHD & $1.97(0.07)$ & $1.33(0.08)$ & $2.53(0.11)$ \\
Depression & $3.36(0.12)$ & $3.85(0.19)$ & $2.94(0.16)$ \\
Presence of friends & $2.90(0.01)$ & $2.93(0.01)$ & $2.87(0.02)$ \\
Stability: best friend & $39.6 \%$ & $42.1 \%$ & $37.5 \%$ \\
Stability: top three friends & $62.3 \%$ & $65.2 \%$ & $59.8 \%$ \\
Quality: best friend & $34.81(0.21)$ & $37.14(0.28)$ & $32.78(0.30)$ \\
Quality: top three friends & $10.84(0.04)$ & $10.81(0.05)$ & $10.86(0.05)$ \\
Classroom friendship group: total difficulties & $7.99(0.20)$ & $7.18(0.22)$ & $8.70(0.24)$ \\
Classroom friendship group: cooperativeness & $0.51(0.01)$ & $0.54(0.01)$ & $0.47(0.01)$ \\
Classroom friendship group: disruptiveness & $0.12(0.005)$ & $0.07(0.005)$ & $0.17(0.01)$ \\
Number of people in classroom friendship group & $4.98(0.07)$ & $4.59(0.08)$ & $5.33(0.10)$ \\
\hline
\end{tabular}

$n=1712(53.5 \%$ male), $A D H D$ attention deficit/hyperactivity disorder, $S E$ standard error

\section{Associations of ADHD, Features of Friendship and Depression}

ADHD symptoms at baseline were associated with naming fewer friends and lower friendship quality at baseline, both of which were associated with increased depressive symptoms at follow-up. ADHD symptoms were also associated with being part of a classroom friendship group that had higher total difficulties and was rated as less cooperative and more disruptive at baseline. Stability of the best friendship from baseline to follow-up was inversely associated with depressive symptoms (Table 2). ADHD symptoms were associated with depressive symptoms 7 months later $(b=0.48(95 \%$ CI $0.17,0.79) p=0.002)$.

\section{Indirect Effects via Friendship in the ADHD-Depression Association}

ADHD and depressive symptoms were associated directly and indirectly via friendship quality, both for best friend and top three friends, when tested separately (Table 2). They showed independent effects when tested simultaneously in a multiple mediator model (Table 3), each accounting for approximately $9 \%$ of the total effect of ADHD symptoms on subsequent depressive symptoms. Sensitivity analyses suggested that the best friendship quality sub-scales of higher friendship conflict and lower friendship security drove this effect (Supplement 5).

The indirect effect of ADHD symptoms on depressive symptoms via friendship quality was larger for females than males (Supplement 6).

Table 2 Associations of ADHD Symptoms, Friendship Variables and Depressive Symptoms

\begin{tabular}{lccc}
\hline Friendship variable & $\begin{array}{l}\text { ADHD symptoms association } \\
\text { with variable }(b(95 \% \mathrm{CI}) p)\end{array}$ & $\begin{array}{l}\text { Variable association with } \\
\text { depressive symptoms } \\
(b(95 \% \mathrm{CI}) p)\end{array}$ & $\begin{array}{l}\text { Indirect effect via variable between } \\
\text { ADHD and depressive symptoms } \\
(b(95 \% \mathrm{CI}) p)\end{array}$ \\
\hline Presence of friends & $-0.05(-0.08,-0.02) 0.002$ & $-0.65(-1.24,-0.07) 0.029$ & $0.03(-0.004,0.06) 0.095$ \\
Stability: best friend & OR $=0.92(0.80,1.06) 0.267$ & $-0.57(-1.07,-0.06) 0.027$ & $0.01(-0.01,0.03) 0.262$ \\
Stability: top three friends & $\mathrm{OR}=0.96(0.82,1.12) 0.568$ & $-0.32(-0.84,0.21) 0.235$ & $0.004(-0.01,0.02) 0.530$ \\
Quality: best friend & $-0.75(-1.29,-0.20) 0.008$ & $-0.72(-0.97,-0.47)<0.001$ & $0.06(0.01,0.11) 0.011$ \\
Quality: top three friends & $-0.15(-0.25,-0.05) 0.003$ & $-0.69(-0.94,-0.44)<0.001$ & $0.07(0.02,0.11) 0.008$ \\
Classroom friendship group: total difficulties & $0.94(0.61,1.27)<0.001$ & $0.17(-0.10,0.43) 0.211$ & $0.02(-0.05,0.08) 0.633$ \\
Classroom friendship group: cooperativeness & $-0.03(-0.04,-0.02)<0.001$ & $-0.03(-0.29,0.23) 0.798$ & $-0.01(-0.06,0.04) 0.663$ \\
Classroom friendship group: disruptiveness & $0.03(0.02,0.04)<0.001$ & $0.15(-0.12,0.42) 0.262$ & $-0.01(-0.05,0.08) 0.743$
\end{tabular}

$n=1712, A D H D$ attention deficit/hyperactivity disorder, $b$ unstandardized beta, $C I$ confidence interval, $O R$ odds ratio 
Table 3 Indirect Effects via Friendship Quality and Satisfaction in the Association of ADHD and Depressive Symptoms in a Multiple Mediator Model

\begin{tabular}{llll}
\hline Effect & $b(95 \% \mathrm{CI})$ & $p$ & $\begin{array}{l}\text { Percentage of } \\
\text { total effect medi- } \\
\text { ated }\end{array}$ \\
\hline $\begin{array}{l}\text { Indirect Effect Via } \\
\text { Best Friendship } \\
\text { Quality }\end{array}$ & $0.04(0.01,0.08)$ & 0.024 & $9.05 \%$ \\
$\begin{array}{l}\text { Indirect Effect Via } \\
\quad \text { Top Three Friend- } \\
\text { ships Quality }\end{array}$ & $0.05(0.006,0.09)$ & 0.024 & $9.48 \%$ \\
$\begin{array}{l}\text { Total Indirect Effect } \\
\text { Direct Effect }\end{array}$ & $0.09(0.03,0.15)$ & 0.002 & $18.53 \%$ \\
Total Effect & $0.39(0.09,0.70)$ & 0.011 & - \\
\hline
\end{tabular}

$n=1712, A D H D$ attention deficit/hyperactivity disorder, $b$ unstandardized beta, $C I$ confidence interval

\section{Moderation of Indirect Effects by Parent-Child Relationships}

Most (98.0\%) children reported that they had been in contact with their mother in the last month and $92.5 \%$ with their father. Indirect effects via top three friendships quality attenuated $(p=0.040)$ as mother-child relationship warmth increased (Fig. 1; Supplements 7 $\& 8$ ). Results were suggestive of this moderating effect by mother warmth acting on both paths in the indirect effect via friendship quality between ADHD and depressive symptoms (Fig. 2; Supplement 8). Indirect effects via top three friendships quality also attenuated slightly as fatherchild hostility decreased, though this observation did not

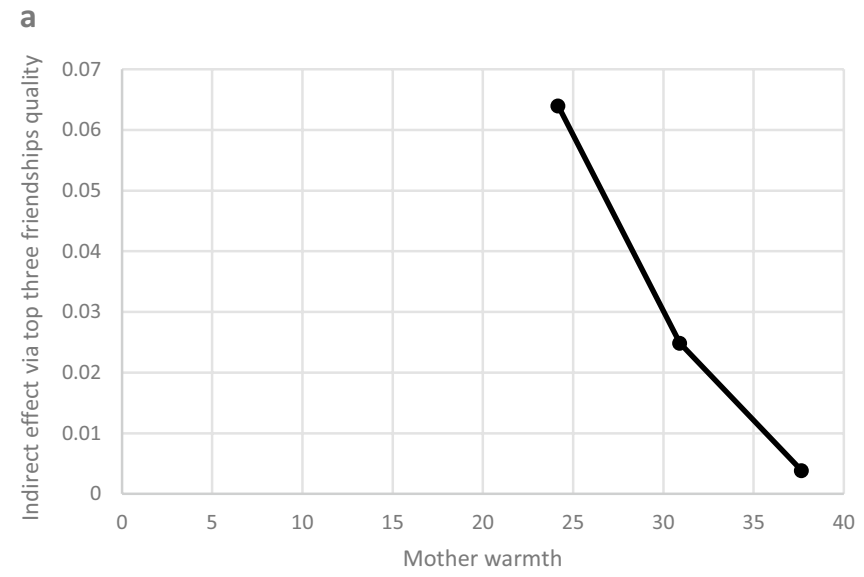

Fig. 1 Plots of Moderated Mediation. Moderated mediation analysis suggested that when mother warmth increased, the indirect effect (beta) via quality of friendship with top three friends between ADHD and depressive symptoms attenuated (a). When father hostility decreased, the indirect effect via quality of friendship with top three friends also attenuated slightly (b), though this did not meet reach the conventional threshold for statistical significance $(p=0.084)$ (Fig. 1; Supplement 7).

All results were very similar before and after imputation (Supplement 9).

\section{Discussion}

To our knowledge, this is the first detailed investigation of how different aspects of friendships are involved in the prospective association of ADHD and depressive symptoms. We also investigated whether parent-child relationship quality moderated any indirect effects via friendship in the prospective association of ADHD and depressive symptoms. In a representative longitudinal study of children, ADHD symptoms were associated with children having fewer friends and lower quality friendships, which were both associated with depressive symptoms. ADHD symptoms were also associated with having a classroom friendship group that had more total difficulties, was more disruptive and less cooperative. Retaining best friendships across the study period was inversely associated with depression symptoms. These findings build upon case-control studies that found an association between ADHD and having fewer friends, more friendship conflict and aggression (Blachman \& Hinshaw, 2002) and an increased likelihood of being friends with a child with a learning or behaviour problem (Marton et al., 2015), and an association between poor friendship quality and depression (Goodyer et al., 1989). Despite these varied associations, only friendship quality was identified as a pathway through which ADHD symptoms were associated with subsequent depressive symptoms. The indirect effect

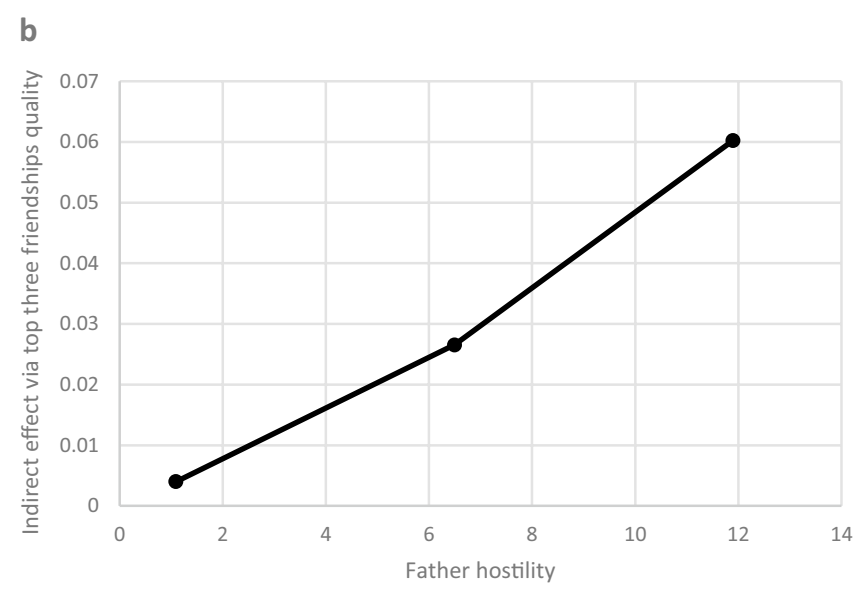

conventional thresholds for statistical significance. The model tested included interaction effects on the path between ADHD symptoms and friendship quality and on the path between friendship quality and depressive symptoms. Indirect effect betas at the mean of the moderator and the mean \pm 1 standard deviation are plotted $(n=1712)$ 
Fig. 2 Moderated Mediation Model. Results supported a model whereby friendship quality accounted for part of the association between ADHD symptoms and depressive symptoms (black arrow) via mediated pathways (dashed dark grey arrows). There was some evidence to suggest that the indirect effect via top three friendships quality might be moderated by parent-child relationships (dotted light grey arrows), whereby warmer, less hostile relationships with mothers and fathers slightly decreased the size of the indirect effect

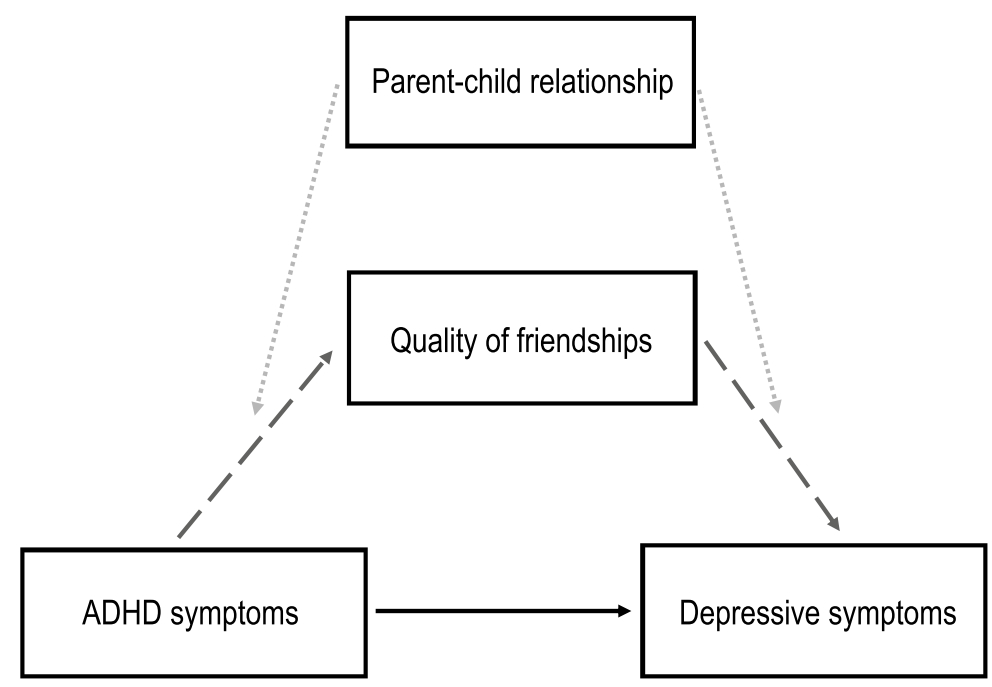

via top three friendships quality varied slightly in magnitude according to the warmth and hostility of parent-child relationships, suggesting that positive parent-child relationships might mitigate some of the adverse effects in the indirect pathway of ADHD to depressive symptoms via poor quality friendships.

The findings on friendship quality align with theories of social difficulty explaining some of the link between early psychopathology and subsequent depression (Capaldi, 1992). Our findings suggest this is also a pathway that links ADHD to depression symptoms. Friendship quality as a form of perceived social support might reduce depression risk in those with elevated ADHD symptoms via increasing a sense of connectedness and self-esteem, or by buffering against life stresses (Rueger et al., 2016). Those with ADHD are more likely to experience adversity in various areas of life (Harpin, 2005) and good social support can mitigate against depressive outcomes in those who experience adversity (Collishaw et al., 2016; Lee et al., 2019). Sensitivity analyses showed that conflict and security with friends (ability to disclose problems to friend and reconcile after disagreement) appeared to be the specific elements of friendship quality that were important in the pathway from ADHD to depressive symptoms. Elevated conflict with friends has been reported for children with ADHD (Blachman \& Hinshaw, 2002) and poor-quality friendships may also be risk factors for depressive outcomes in school aged children (Goodyer et al., 1989).

Larger indirect effects via friendship quality were observed in females than males. This aligns with previous evidence of females valuing aspects of friendship quality such as companionship and intimacy more highly than males (Hall, 2010). Interpersonal stress may be more prevalent and predictive of depression in adolescent females than males (Shih et al., 2006), particularly in females with ADHD, who may experience more peer-relationship difficulties than males with ADHD (Elkins et al., 2011). However, it seems likely that the indirect effects observed are important to consider for both sexes.

There was some evidence of moderated mediation suggesting that indirect effects of top three friendships quality on the link between ADHD and depressive symptoms decreased slightly as self-reports of mother-child relationship warmth increased and father-child relationship hostility decreased, though the evidence for father hostility did not reach the conventional significance threshold. This draws attention to the need to consider the child's social support across different contexts such as the parent-child relationship. Findings were suggestive of mother warmth moderating both the ADHD symptoms to friendship quality path and the friendship quality to depression symptoms path of the indirect effect. This finding is consistent with that of a previous study that found an association between parental behaviour and child peer-relationships in children with ADHD (Mikami et al., 2010) in addition to studies that have found parent-child relationships may be able to compensate for a lack of friends (Stocker, 1994) and mitigate against poor mental health in the presence of adversity (Brennan et al., 2003; Collishaw et al., 2007, 2016; Lewandowski et al., 2014). However, these moderated mediation findings should be interpreted with caution given that results were not consistent across mother and father or between warmth and hostility. Nevertheless, this may be explained in part by previous findings that suggest mothers and fathers may have differential effects on the friendships of their adolescent children (Flynn et al., 2018; Updegraff et al., 2001). 
For instance, one study found that while mother supportive behaviour and hostile behaviour influenced their children's interactional style with peers, for fathers, it was their problem-solving behaviour and hostile behaviour that appeared to be important (Flynn et al., 2018). Moderated mediation results in the current study were also inconsistent across the two friendship quality measures used. While some evidence of moderation by mother warmth was observed for the indirect effect via friendship quality with the top three friends, strong evidence of moderation by parent-child relationship quality was not found for the indirect effect via friendship quality with the best friend. Measurement differences in the two friendship variables used in the present study may have affected the findings, as a previous study found evidence of an interaction of friendship stability with a variable measuring quality of top three friendships, which was not found for the quality of the best friendship only ( $\mathrm{Ng}$-Knight et al., 2019).

Limitations include that we relied on teacher reports of child ADHD symptoms which provide a reliable measure of ADHD symptoms in school, but most clinical research and practitioners rely primarily on parental reports of symptoms. In addition, while the SDQ hyperactivity-inattention subscale completed by teachers is a valid and useful screening tool for ADHD (Goodman, 1997), it is not a diagnostic measure and we were not able to investigate whether ADHD inattentive or hyperactive-impulsive subtypes were differentially associated with friendship or depression in this study. The inattentive subtype has been found to be the most common subtype in population samples, particularly during adolescence (Willcutt, 2012). Associations between ADHD and emotional and peer problems may vary according to subtype (Graetz et al., 2001), and thus subtype differences are of interest for future research. Despite the longitudinal design used, there is a possibility that reverse causation contributed to observed associations. However, evidence suggests that ADHD precedes depression in a potentially causal relationship (Riglin et al., 2020) and that the prospective relationship exists over long periods of time and when adjusting for prior emotional disorder symptomatology (Powell et al., 2020). Moreover, a sensitivity check found that ADHD symptoms were associated with subsequent depressive symptoms when adjusting for baseline self-reported SDQ emotional problems (Goodman, 1997; Supplement 9). Although we tested indirect effects, this is not mediation analysis per se, due to exposure and mediator being measured contemporaneously (Selig \& Preacher, 2009). This study had missing data, a common problem in longitudinal data (Spratt et al., 2010). However, tests were adjusted for confounders that predicted missingness, helping to address potential bias arising from missing data (Groenwold et al., 2012). Additionally, we conducted Multiple Imputation and results remained very similar in imputed data, suggesting bias caused by missingness was minimal (Spratt et al., 2010). Those with ADHD may under-report their depressive symptoms and over-report their social competence, while those with depression might underrate their social ability, which could attenuate associations (Fraser et al., 2018; Ohan \& Johnston, 2011; Whitton et al., 2008). In addition, we were unable to investigate whether the friendships reported by the children were reciprocated in the current study, due to reported best friends not necessarily attending the same school. However, children were asked to report only their top three friendships - an approach that has been used previously (Fowler et al., 2007; Ng-Knight et al., 2019). Children were asked to report their best three friends rather than to report a total number of friends to capture the children's close friendships, thereby helping to avoid some of the positive illusory bias that may affect reporting on friendships in children with ADHD symptoms. While measures of how many friends a child has in total may capture how popular or liked that individual is on a group level (e.g., in their class or school), measures that capture children's close friendships may be more predictive of later adjustment and depression (Narr et al., 2019; Schneider et al., 1994). In addition, while self-rated measures of friendship presence and quality were used, peer-rated classroom data was also used to measure the characteristics of the friendship group, which also might help to mitigate against any effect of illusory biases. ADHD symptoms were associated with characteristics of the classroom friendship group (a peer-rated variable), though it did not act as a mediator of the association between ADHD and depressive symptoms in the current study.

Strengths include use of a representative school-based sample during the first year of secondary school with detailed information from multiple informants on different features of friendship, in addition to parent-child relationship quality. School life and transitions are important in adolescent mental health and may be particularly challenging for those with ADHD (Ford, 2020; Richardson et al., 2015).

Implications of this work include pinpointing quality of friendships and parent-child relationships as important to consider clinically in those with ADHD for reducing depression risk. Many peer relationship-focused interventions, which have mainly focused on peer acceptance and social skills thus far, have shown little success in children with neurodevelopmental disorders (Mikami, 2010). Promising directions for the development of enhanced programmes include those involving a parental component focused on dyadic friendship building (Gardner et al., 2019). Schools' arrangements regarding awareness of friendship groups (e.g., keeping together or separating friends) are also important in ensuring children feel settled at the beginning of secondary school (Keay et al., 2015), and may need additional consideration in children with ADHD. Practical implications for children with ADHD in mitigating later risk of emotional 
difficulties may also involve focusing on interventions to strengthen parent-child relationships (Abikoff et al., 2015; Meinzer et al., 2020). Interventions aiming to improve parent-child interactions can have beneficial effects on the mental health of both child and parent (Sonuga-Barke et al., 2001).

\section{Conclusion}

We found in a large school-based sample that ADHD symptoms were associated with subsequent depressive symptoms partly via decreased friendship quality, suggesting that this aspect of friendship is one potential mechanism by which ADHD symptoms increase risk for depressive symptoms. Positive features of parent-child relationships seemed to slightly alleviate the indirect effect via friendship quality, highlighting the importance of considering different sources of social support in the child's life.

Supplementary Information The online version contains supplementary material available at https://doi.org/10.1007/s10802-021-00798-w.

Acknowledgements We thank the participating schools, pupils and parents in the School Transition and Adjustment Research Study (www.ucl. ac.uk/stars). The STARS project was funded by the Nuffield Foundation (EDU/40065), but the views expressed are those of the authors and not necessarily those of the Nuffield Foundation (www.nuffieldfoundation. org). This publication is the work of the authors and Victoria Powell will serve as guarantor for the contents of this paper.

\section{Compliance with Ethical Standards}

Conflict of Interest The authors declare that they have no conflict of interest.

Open Access This article is licensed under a Creative Commons Attribution 4.0 International License, which permits use, sharing, adaptation, distribution and reproduction in any medium or format, as long as you give appropriate credit to the original author(s) and the source, provide a link to the Creative Commons licence, and indicate if changes were made. The images or other third party material in this article are included in the article's Creative Commons licence, unless indicated otherwise in a credit line to the material. If material is not included in the article's Creative Commons licence and your intended use is not permitted by statutory regulation or exceeds the permitted use, you will need to obtain permission directly from the copyright holder. To view a copy of this licence, visit http://creativecommons.org/licenses/by/4.0/.

\section{References}

Abikoff, H. B., Thompson, M., Laver-Bradbury, C., Long, N., Forehand, R. L., Miller Brotman, L., \& Sonuga-Barke, E. (2015). Parent training for preschool ADHD: a randomized controlled trial of specialized and generic programs. Journal of Child Psychology and Psychiatry, 56(6), 618-631.
American Psychiatric Association. (1994). Diagnostic and Statistical Manual of Mental Disorders (DSM-IV) (4th ed.). Author.

American Psychiatric Association. (2013). Diagnostic and Statistical Manual of Mental Disorders (DSM-V) (5th edn.) (5th ed.). American Psychiatric Publishing.

Angold, A., Costello, E., Messer, S., Pickles, A., Winder, F., \& Silver, D. (1995). Development of a questionnaire for use in epidemiological studies of depression in children and adolescents. International Journal of Methods in Psychiatric Research, 5(4), 237-249.

Blachman, D. R., \& Hinshaw, S. P. (2002). Patterns of friendship among girls with and without attention-deficit/hyperactivity disorder. Journal of Abnormal Child Psychology, 30(6), 625-640.

Brennan, P. A., Le Brocque, R., \& Hammen, C. (2003). Maternal depression, parent-child relationships, and resilient outcomes in adolescence. Journal of the American Academy of Child and Adolescent Psychiatry, 42(12), 1469-1477.

Bukowski, W. M., Hoza, B., \& Boivin, M. (1994). Measuring friendship quality during pre- and early adolescence: the development and psychometric properties of the friendship qualities scale. Journal of Social and Personal Relationships, 11(3), 471-484.

Bukowski, W. M., Newcombe, A. F., \& Hartup, W. W. (1996). Friendship and its significance in childhood and adolescence: Introduction and comment. In W. M. Bukowski, A. F. Newcombe, \& W. W. Hartup (Eds.), The company they keep: Friendship in childhood and adolescence (pp. 1-19). Cambridge University Press.

Cabrera, N. J., Volling, B. L., \& Barr, R. (2018). Fathers are parents, too! Widening the lens on parenting for children's development. Child Development Perspectives, 12(3), 152-157.

Cairns, R. B., \& Cairns, B. D. (1994). Lifelines and risks: pathways of youth in our time. Cambridge University Press.

Cairns, R. B., Cairns, B. D., Neckerman, H. J., Gest, S. D., \& Gariépy, J. L. (1988). Social networks and aggressive behavior: peer support or peer rejection? Developmental Psychology, 24(6), $815-823$.

Cairns, R. B., Leung, M.-C., Buchanan, L., \& Cairns, B. D. (1995). Friendships and social networks in childhood and adolescence: fluidity, reliability, and interrelations. Child Development, 66(5), 1330-1345

Capaldi, D. M. (1992). Co-occurrence of conduct problems and depressive symptoms in early adolescent boys: II. A 2-year follow-up at Grade 8. Development and Psychopathology, 4(1), 125-144.

Chung, H., Elias, M., \& Schneider, K. (1998). Patterns of individual adjustment changes during middle school transition. Journal of School Psychology, 36(1), 83-101.

Coie, J. D., \& Dodge, K. A. (1988). Multiple sources of data on social behavior and social status in the school: a cross-age comparison. Child Development, 59(3), 815-829.

Cole, D. A. (1990). Relation of social and academic competence to depressive symptoms in childhood. Journal of Abnormal Psychology, 99(4), 422-429.

Collishaw, S., Hammerton, G., Mahedy, L., Sellers, R., Owen, M. J., Craddock, N., \& Thapar, A. (2016). Mental health resilience in the adolescent offspring of parents with depression: a prospective longitudinal study. The Lancet Psychiatry, 3(1), 49-57.

Collishaw, S., Pickles, A., Messer, J., Rutter, M., Shearer, C., \& Maughan, B. (2007). Resilience to adult psychopathology following childhood maltreatment: evidence from a community sample. Child Abuse and Neglect, 31(3), 211-229.

Deković, M., \& Meeus, W. (1997). Peer relations in adolescence: effects of parenting and adolescents' self-concept. Journal of Adolescence, 20(2), 163-176.

Deng, L., \& Chan, W. (2017). Testing the difference between reliability coefficients alpha and omega. Educational and Psychological Measurement, 77(2), 185-203. 
Elkins, I. J., Malone, S., Keyes, M., Iacono, W. G., \& McGue, M. (2011). The impact of attention-deficit/hyperactivity disorder on preadolescent adjustment may be greater for girls than for boys. Journal of Clinical Child \& Adolescent Psychology, 40(4), 532-545.

Flynn, H. K., Felmlee, D. H., Shu, X., \& Conger, R. D. (2018). Mothers and fathers matter: the influence of parental support, hostility, and problem solving on adolescent friendships. Journal of Family Issues, 39(8), 2389-2412.

Flynn, M., \& Rudolph, K. D. (2011). Stress generation and adolescent depression: contribution of interpersonal stress responses. Journal of Abnormal Child Psychology, 39(8), 1187-1198.

Ford, T. (2020). Transitional care for young adults with ADHD: transforming potential upheaval into smooth progression. Epidemiology and Psychiatric Sciences, 29, e87.

Fowler, T., Shelton, K., Lifford, K., Rice, F., McBride, A., Nikolov, I., \& Van Den Bree, M. B. M. (2007). Genetic and environmental influences on the relationship between peer alcohol use and own alcohol use in adolescents. Addiction, 102(6), 894-903.

Fraser, A., Cooper, M., Agha, S. S., Collishaw, S., Rice, F., Thapar, A., \& Eyre, O. (2018). The presentation of depression symptoms in attention-deficit/hyperactivity disorder: Comparing child and parent reports. Child and Adolescent Mental Health, 23(3), 243-250.

Gardner, D. M., Gerdes, A. C., \& Weinberger, K. (2019). Examination of a parent-assisted, friendship-building program for adolescents with ADHD. Journal of Attention Disorders, 23(4), 363-373.

Gilman, S. E., Kawachi, I., Fitzmaurice, G. M., \& Buka, S. L. (2002). Socioeconomic status in childhood and the lifetime risk of major depression. International Journal of Epidemiology, 31(2), 359-367.

Goodman, R. (1997). The strengths and difficulties questionnaire: a research note. Journal of Child Psychology and Psychiatry, 38, 581-586.

Goodman, R., Ford, T., Simmons, H., Gatward, R., \& Meltzer, H. (2000). Using the strengths and difficulties questionnaire (SDQ) to screen for child psychiatric disorders in a community sample. British Journal of Psychiatry, 177(6), 534-539.

Goodyer, I. M., Wright, C., \& Altham, P. M. E. (1989). Recent friendship in anxious and depressed school age children. Psychological Medicine, 19, 165-174.

Graetz, B. W., Sawyer, M. G., Hazell, P. L., Arney, F., \& Baghurst, P. (2001). Validity of DSM-IV ADHD subtypes in a nationally representative sample of Australian children and adolescents. Journal of the American Academy of Child \& Adolescent Psychiatry, 40(12), 1410-1417.

Groenwold, R. H. H., Donders, A. R. T., Roes, K. C. B., Harrell, F. E. J., \& Moons, K. G. M. (2012). Dealing with missing outcome data in randomized trials and observational studies. American Journal of Epidemiology, 175(3), 210-217.

Hall, J. A. (2010). Sex differences in friendship expectations: a metaanalysis. Journal of Social and Personal Relationships, 28(6), 723-747.

Hamm, J. V., Farmer, T. W., Dadisman, K., Gravelle, M., \& Murray, A. R. (2011). Teachers' attunement to students' peer group affiliations as a source of improved student experiences of the school social-affective context following the middle school transition. Journal of Applied Developmental Psychology, 32(5), 267-277.

Harpin, V. A. (2005). The effect of ADHD on the life of an individual, their family, and community from preschool to adult life. Archives of Disease in Childhood, 90, i2-i7.

Humphreys, K. L., Katz, S. J., Lee, S. S., Hammen, C., Brennan, P. A., \& Najman, J. M. (2013). The association of ADHD and depression: mediation by peer problems and parent-child difficulties in two complementary samples. Journal of Abnormal Psychology, 122(3), 854-867.
Keay, A., Lang, J., \& Frederickson, N. (2015). Comprehensive support for peer relationships at secondary transition. Educational Psychology in Practice, 31(3), 279-292.

Larson, R., \& Richards, M. H. (1991). Daily companionship in late childhood and early adolescence: changing developmental contexts. Child Development, 62(2), 284-300.

Lee, H. Y., Oh, J., Kawachi, I., Heo, J., Kim, S., Lee, J. K., \& Kang, D. (2019). Positive and negative social support and depressive symptoms according to economic status among adults in Korea: Cross-sectional results from the Health Examinees-Gem Study. British Medical Journal Open, 9(4), 1-10.

Lewandowski, R. E., Verdeli, H., Wickramaratne, P., Warner, V., Mancini, A., \& Weissman, M. (2014). Predictors of positive outcomes in offspring of depressed parents and non-depressed parents across 20 years. Journal of Child and Family Studies, 23(5), 800-811.

Ljung, T., Chen, Q., Lichtenstein, P., \& Larsson, H. (2014). Common Etiological Factors of Attention-Deficit/Hyperactivity Disorder and Suicidal Behavior: A Population-Based Study in Sweden. JAMA Psychiatry, 71(8), 958-964.

Marton, I., Wiener, J., Rogers, M., \& Moore, C. (2015). Friendship characteristics of children with ADHD. Journal of Attention Disorders, 19(10), 872-881.

Meinzer, M. C., Felton, J. W., Oddo, L. E., Rubin, K. H., \& ChronisTuscano, A. (2020). Do ADHD symptoms and relationship quality with mothers and best friends across high school predict depressive symptoms for adolescents? Journal of Attention Disorders.

Meinzer, M. C., Pettit, J. W., \& Viswesvaran, C. (2014). The cooccurrence of attention-deficit/hyperactivity disorder and unipolar depression in children and adolescents: A meta-analytic review. Clinical Psychology Review, 34(8), 595-607.

Melby, J. N., \& Conger, R. D. (2001). The Iowa Family Interaction Rating Scales: Instrument summary. Family Observational Coding Systems: Resources for Systemic Research., pp. 33-58. Mahwah, NJ, US: Lawrence Erlbaum Associates Publishers.

Mikami, A. Y. (2010). The importance of friendship for youth with attention-deficit/hyperactivity disorder. Clinical Child and Family Psychology Review, 13(2), 181-198.

Mikami, A. Y., Jack, A., Emeh, C. C., \& Stephens, H. F. (2010). Parental influence on children with attention-deficit/hyperactivity disorder: I. Relationships between parent behaviors and child peer status. Journal of Abnormal Child Psychology, 38(6), 721-736.

Mrug, S., Molina, B. S. G., Hoza, B., Gerdes, A. C., Hinshaw, S. P., Hechtman, L., \& Arnold, L. E. (2012). Peer rejection and friendships in children with Attention-Deficit/Hyperactivity Disorder: contributions to long-term outcomes. Journal of Abnormal Child Psychology, 40(6), 1013-1026.

Narr, R. K., Allen, J. P., Tan, J. S., \& Loeb, E. L. (2019). Close friendship strength and broader peer group desirability as differential predictors of adult mental health. Child Development, 90(1), 298-313.

Ng-Knight, T., Shelton, K. H., Riglin, L., Frederickson, N., McManus, I. C., \& Rice, F. (2019). 'Best friends forever'? Friendship stability across school transition and associations with mental health and educational attainment. British Journal of Educational Psychology, 89(4), 585-599.

Ng-Knight, T., Shelton, K. H., Riglin, L., McManus, I. C., Frederickson, N., \& Rice, F. (2016). A longitudinal study of selfcontrol at the transition to secondary school: Considering the role of pubertal status and parenting. Journal of Adolescence, $50,44-55$.

Ohan, J. L., \& Johnston, C. (2011). Positive illusions of social competence in girls with and without ADHD. Journal of Abnormal Child Psychology, 39(4), 527-539.

Parkhurst, J. T., \& Asher, S. R. (1992). Peer rejection in middle school: subgroup differences in behavior, loneliness, and interpersonal concerns. Developmental Psychology, 28, 231-241. 
Patterson, G. R., \& Stoolmiller, M. (1991). Replications of a dual failure model for boys' depressed mood. Journal of Consulting and Clinical Psychology, 59(4), 491-498.

Powell, V., Riglin, L., Hammerton, G., Eyre, O., Martin, J., Anney, R., \& Rice, F. (2020). What explains the link between childhood ADHD and adolescent depression? Investigating the role of peer relationships and academic attainment. European Child \& Adolescent Psychiatry, 29(11), 1581-1591.

Preacher, K. J., Rucker, D. D., \& Hayes, A. F. (2007). Addressing moderated mediation hypotheses: Theory, methods, and prescriptions. Multivariate Behavioral Research, 42(1), 185-227.

Richardson, M., Moore, D. A., Gwernan-Jones, R., Thompson-Coon, J., Ukoumunne, O., Rogers, M., \& Ford, T. J. (2015). Non-pharmacological interventions for attention-deficit/hyperactivity disorder (ADHD) delivered in school settings: systematic reviews of quantitative and qualitative research. Health Technology Assessment, 19(45), 1-470.

Riglin, L., Leppert, B., Dardani, C., Thapar, A. K., Rice, F., O'Donovan, M. C., Thapar, A. (2020). ADHD and depression: investigating a causal explanation. Psychological Medicine, 1-8.

Roy, A., Hartman, C. A., Veenstra, R., \& Oldehinkel, A. J. (2015). Peer dislike and victimisation in pathways from ADHD symptoms to depression. European Child \& Adolescent Psychiatry, 24(8), 887-895.

Rueger, S. Y., Malecki, C. K., Pyun, Y., Aycock, C., \& Coyle, S. (2016). A meta-analytic review of the association between perceived social support and depression in childhood and adolescence. Psychological Bulletin, 142, 1017-1067.

Schneider, B. H., Wiener, J., \& Murphy, K. (1994). Children's friendships: the giant step beyond peer acceptance. Journal of Social and Personal Relationships, 11(3), 323-340.

Selig, J. P., \& Preacher, K. J. (2009). Mediation Models for Longitudinal Data in Developmental Research. Research in Human Development, 6(2-3), 144-164.

Shih, J. H., Eberhart, N. K., Hammen, C. L., \& Brennan, P. A. (2006). Differential exposure and reactivity to interpersonal stress predict sex differences in adolescent depression. Journal of Clinical Child \& Adolescent Psychology, 35(1), 103-115.

Sonuga-Barke, E. J., Daley, D., Thompson, M., Laver-Bradbury, C., \& Weeks, A. (2001). Parent-based therapies for preschool attentiondeficit/hyperactivity disorder: a randomized, controlled trial with a community sample. Journal of the American Academy of Child and Adolescent Psychiatry, 40(4), 402-408.

Spratt, M., Carpenter, J., Sterne, J. A. C., Carlin, J. B., Heron, J., Henderson, J., \& Tilling, K. (2010). Strategies for multiple imputation in longitudinal studies. American Journal of Epidemiology, 172(4), 478-487.
Stocker, C. M. (1994). Children's perceptions of relationships with siblings, friends, and mothers: compensatory processes and links with adjustment. Journal of Child Psychology and Psychiatry, 35(8), 1447-1459.

Thapar, A., \& McGuffin, P. (1998). Validity of the shortened Mood and Feelings Questionnaire in a community sample of children and adolescents: a preliminary research note. Psychiatry Research, $81(2), 259-268$.

UCLA Statistical Consulting Group. (n.d.). How can I compute indirect effects with imputed data? (method 1) I STATA FAQ. Retrieved January 31, 2020, from https://stats.idre.ucla.edu/stata/faq/howcan-i-compute-indirect-effects-with-imputed-data-method-1/

Ulleb $\varnothing$, A. K., Posserud, M.-B., Heiervang, E., Gillberg, C., \& Obel, C. (2011). Screening for the attention deficit hyperactivity disorder phenotype using the strength and difficulties questionnaire. European Child \& Adolescent Psychiatry, 20(9), 451-458.

Updegraff, K. A., McHale, S. M., Crouter, A. C., \& Kupanoff, K. (2001). Parents' involvement in adolescents' peer relationships: a comparison of mothers' and fathers' roles. Journal of Marriage and Family, 63(3), 655-668.

White, I. R., Royston, P., \& Wood, A. M. (2011). Multiple imputation using chained equations: issues and guidance for practice. Statistics in Medicine, 30(4), 377-399.

Whitton, S. W., Larson, J. J., \& Hauser, S. T. (2008). Depressive symptoms and bias in perceived social competence among young adults. Journal of Clinical Psychology, 64(7), 791-805.

Willcutt, E. G. (2012). The prevalence of DSM-IV attention-deficit/ hyperactivity disorder: a meta-analytic review. Neurotherapeutics, 9(3), 490-499.

Williams, E. D., Tillin, T., Richards, M., Tuson, C., Chaturvedi, N., Hughes, A. D., \& Stewart, R. (2015). Depressive symptoms are doubled in older British South Asian and Black Caribbean people compared with Europeans: associations with excess co-morbidity and socioeconomic disadvantage. Psychological Medicine, 45(9), 1861-1871.

Zellner, A. (1962). An efficient method of estimating seemingly unrelated regressions and tests for aggregation bias. Journal of the American Statistical Association, 57(298), 348-368.

Publisher's Note Springer Nature remains neutral with regard to jurisdictional claims in published maps and institutional affiliations. 